\title{
Thermal and mechanical stresses in a solar central receiver
}

\author{
A. Montoya $^{1 \mathrm{a}}$, M.R. Rodríguez-Sánchez ${ }^{2 \mathrm{~b}}$, J. López-Puente ${ }^{1}$ and D. Santana ${ }^{2}$ \\ ${ }^{1}$ Department of Structure and Continuous Media. \\ ${ }^{2}$ Department of Thermal and Fluid Engineering \\ Carlos III University of Madrid \\ Campus of Leganés, 28911 Madrid (Spain)
}

Phone/Fax number:+0034 916246034, e-mail: ${ }^{\mathrm{a} a n d m o n t o @ i n g . u c 3 m . e s, ~}{ }^{\mathrm{b}}$ mrrsanch@ing.uc3m.es

\begin{abstract}
Failure in the tubes of the solar receiver is a problem that should be studied. This failure is caused by the combined action of the high temperature, stresses and corrosion.

Commonly, the calculation of the stresses in the receiver tubes is carried out in the crossed sections, taking into account the radial and the circumferential variation of the temperature. However, the temperature gradient along the tube length has been ignored.

In this study a new model for the stress calculation in the receiver tubes has been developed. This model includes the temperature gradient in circumferential, radial, and longitudinal direction, taking into account the movement restrictions.

The results show that the mechanical boundary conditions have a large effect in the stresses of the tube, being 3 times higher than the stress when no movement restrictions have been imposed. Moreover, the stress profile is highly dependent on the temperature gradient and hence on the incident solar flux on the receiver. Homogeneous solar fluxes are then more suitable than lower levels of solar fluxes with important gradients.
\end{abstract}

\section{Key words}

Solar power tower, solar receiver, thermal gradient, thermal stresses, FEM analysis.

\section{Introduction}

Nowadays, energy production with renewable sources is fundamental. Wind and photovoltaic energy are the technologies with higher future projection due to the low cost of the energy produced. However, these technologies are intermittent and cannot be adapted to the energy demand of the society.

To achieve standing alone of the renewable energy production flexible energy source is required. Then, concentrated solar power with thermal storage emerges as an important back up source of renewable energy [1]. Within this category solar power tower, using molten salt as heat transfer fluid, is particularly relevant.
Receivers working with molten salt generally are tubular external receivers. The tubes of the receivers are exposed to high and cyclic solar flux that provokes high temperature and stresses on the tube material. These extreme operational conditions cause prompt failure of the receivers, which should be avoided using more homogeneous heat fluxes.

Direct measurements of incident flux density, stress and temperature of the receiver material, during operation, are almost impossible. Therefore, numerous researchers have focused their studies in developing thermal and mechanical models of the solar receivers. Gertig et al. [2] developed a thermo-economical model in which realised the importance of combining the different subsystems of the solar power plant to optimise its operation. MarugánCruz et al. [3] developed a detailed thermal model for tubes non-uniformly heated. This model considers that the dominant heat flux is the radial one, and it is only valid for high Biot numbers. They calculated the thermal stresses of the tubes, but they did in different cross sections of tube, ignoring the length of the tubes and their deformation. Du et al. [4] presented a five-step model to calculate the thermal stress and fatigue fracture in a single tube of molten salt receivers. They considered half of the tube adiabatic, and the stresses were calculated by solving the stress equation due to temperature gradients. However, the deformations associated to the temperature gradient were again not taken into account.

As can be seen, most of the published studies underestimate the stresses on the receiver. Traditionally, the stresses taken into account are those caused by the temperature gradient (thermal stresses); neglecting that the non-uniform temperature induces tube deformation. In external receivers the tube deformation is avoided by fastening, called clips. Therefore, these clips induce stresses in the tubes (mechanical stresses) that are even higher than the thermal stresses.

In this research both thermal and mechanical stresses have been analysed in tube receivers. Firstly, the model 
used to carry out the analysis has been described. Secondly, the stresses and deformations in a receiver tube subjected at different boundary conditions have been compared. In the first case the tube is embedded in one edge and free in the other, while in the second case the tube has been fixed by clips along its length. Finally, the effect of different incident solar fluxes on a receiver tube has been analysed.

\section{Studied geometry}

To calculate the thermal and mechanical stresses in a receiver tube, a plant similar to Gemasolar has been analysed. Gemasolar is sited on Seville, Spain, and it is in operation since 2011 [5].

The solar field is radial staggered layout, and the position of each heliostat has been determined with scaled aerial images of the SPTs. Gemasolar field consists of 2,650 square heliostats of $10.95 \mathrm{~m}$ side.

Gemasolar uses molten salt as heat transfer fluid in a cylindrical external receiver. The receiver is located at the top of a tower $120 \mathrm{~m}$ high, being the receiver length $(L)$ $10 \mathrm{~m}$. The aspect ratio of the receiver is 1.17 . The circular perimeter is composed by 18 vertical panels, and each of them includes 60 tubes of $2.24 \mathrm{~cm}$ diameter and $1.2 \mathrm{~mm}$ thickness. The tube material is alloy $800 \mathrm{H}$, whose both thermal and mechanical properties varies in function of the temperature as the supplier indicates in [6].

The molten salt analysed is solar salt $\left(60 \% \mathrm{NaNO}_{3}-40 \%\right.$ $\mathrm{KNO}_{3}$ ). It has been considered that its thermal properties depend on the temperature as Zavoico pointed in [7]. The salt enters by the north side of the receiver at $290{ }^{\circ} \mathrm{C}\left(T_{\text {in }}\right)$ and exits by the south side at $565^{\circ} \mathrm{C}$. Then, there are two different flow paths the eastern flow path and the western flow path. The mass flow rate of solar salt in the receiver $\left(n k_{\text {salt }}\right)$ depends on the incident solar flux.

Table I summarizes the main parameters of the solar power tower analysed.

Table I. - Main parameters of Gemasolar.

\begin{tabular}{|c|c|c|c|}
\hline $\begin{array}{c}\text { Number of } \\
\text { heliostats }\end{array}$ & 2650 & Tube diameter [m] & 0.0224 \\
\hline $\begin{array}{c}\text { Heliostat surface } \\
{\left[\mathrm{m}^{2}\right]}\end{array}$ & 120 & Tube thickness [m] & 0.0012 \\
\hline \begin{tabular}{c} 
Tower height $[\mathrm{m}]$ \\
\hline $\begin{array}{c}\text { Receiver length } \\
{[\mathrm{m}]}\end{array}$
\end{tabular} & 120 & $\begin{array}{c}\text { Inlet temperature } \\
{\left[{ }^{\circ} \mathrm{C}\right]}\end{array}$ & 290 \\
\hline $\begin{array}{c}\text { Receiver diameter } \\
{[\mathrm{m}]}\end{array}$ & 8.5 & $\begin{array}{c}\text { Outlet temperature } \\
{\left[{ }^{\circ} \mathrm{C}\right]}\end{array}$ & 565 \\
\hline $\begin{array}{c}\text { Number of panels } \\
\text { temperature }\left[{ }^{\circ} \mathrm{C}\right]\end{array}$ & 18 & $\begin{array}{c}\text { Ambient pressure } \\
{[\text { bar }]}\end{array}$ & 1 \\
\hline $\begin{array}{c}\text { Number of flow } \\
\text { paths }\end{array}$ & 2 & $\begin{array}{c}\text { Fouling resistance } \\
{\left[\mathrm{m}^{2} \mathrm{~K} / \mathrm{W}\right]}\end{array}$ & $0.85 \cdot 10^{-5}$ \\
\hline $\begin{array}{c}\text { Tubes per panel } \\
{[-]}\end{array}$ & 60 & $\begin{array}{c}\text { Tube absorptivity } \\
\text { Tuber }\end{array}$ & 0.95 \\
\hline
\end{tabular}

\section{Methodology}

To solve the stress profile in the tube receivers, it is required to stablish the incident solar flux and to calculate the temperature profile. In the following subsections the different models used to determine the receiver behaviour have been explained in detail. Figure 1 treats to schematise the followed process.

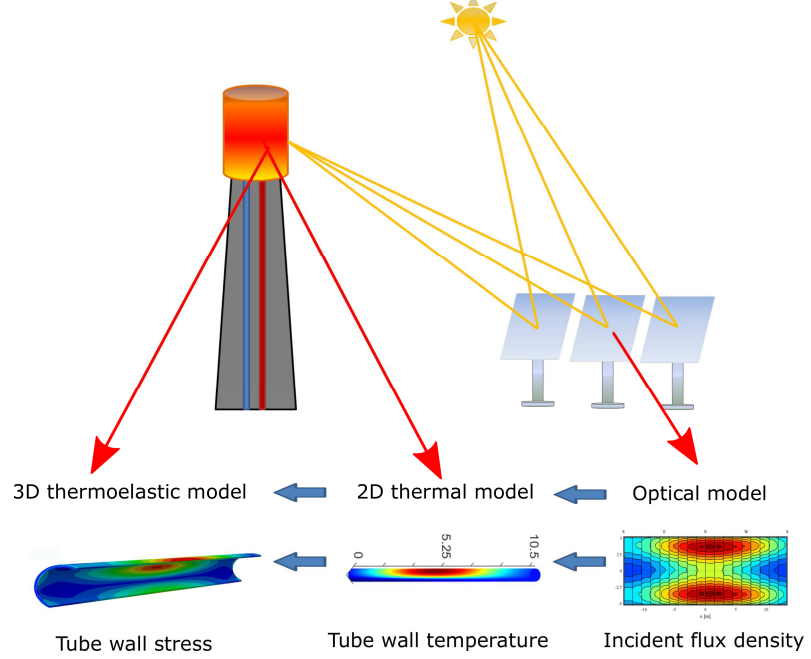

Fig. 1. Schematic of the modelling procedure.

\section{A. Optical and thermal model}

To characterize the thermal behaviour of the receiver several published models have been employed. Firstly, an optical model developed by Sánchez-González and Santana [8] have been used to estimate the incident solar flux on the receiver. Where the concentration ratio is calculated with a projection method, and the flux distribution is based on a circular Gaussian resulting from the convolution of the sunshape and the heliostat slope. This model has low computational cost and can be adapted to different solar fields and receiver geometries. Besides, it allows to modify the aiming strategy.

To characterize the aiming strategy of the solar field it was used the non-dimensional parameter, $\mathrm{k}$, which has been called aiming factor and indicates the probability distribution. By analogy with the circular normal distribution, $68 \%, 95 \%$ and $99.7 \%$ of the total flux is within the cone of aperture angles $\mathrm{k}=1, \mathrm{k}=2$ and $\mathrm{k}=3$, respectively [9]. Symmetric flux maps about the receiver equator with controlled spillage losses are gained through the aiming factor approach.

Once the incident solar flux on the receiver is known, the thermal model developed by Rodríguez-Sánchez et al. [10] has been used to characterize the temperature profile in the tubes. It is a simplified 2D model that only analyses one representative tube per panel, although it considers the effect of the adjacent tubes. The main characteristic of this model is considering circumferential variations of the temperature. Besides, the properties of the HTF and the tube material are dependent of the temperature. Each tube is divided in 20 axial segments 
and 72 circumferential sections. Figure 2 depicts the nodes in which the tubes are divided in the model and the main heat transfer processes.

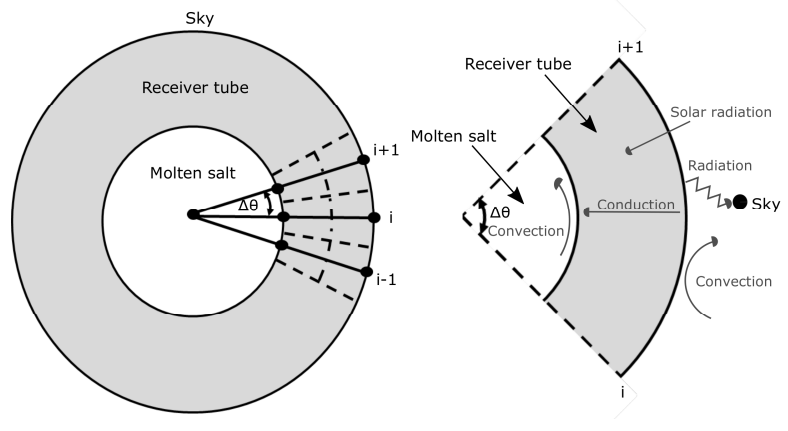

Fig. 2. Optical-thermal conversion process in a receiver tube.

The molten salt temperature and the wall temperature can be calculated as follow. Where, the net heat power absorbed $\left(q_{a b s}\right)$ is calculated as the incident solar flux minus the convective and radiative heat losses, $p$ represents the tube perimeter and $U$ corresponds to the global coefficient of heat transfer, which includes the thermal resistances of conduction, fouling and internal convection.

$$
\begin{gathered}
T_{\text {salt }}=T_{\text {in }}+\frac{L}{n \& \alpha_{\text {salt }} c_{\text {salt }}} \sum_{\theta} q_{a b s} p \\
T_{\text {wall }}=T_{\text {salt }}+\frac{q_{a b s}}{U}
\end{gathered}
$$

\section{B. Thermoelastic model}

Once the temperature of the tube has been obtained with the thermal model, the data is used in a thermoelastic model in order to calculate the thermal stresses. This model has been developed in FEM program Abaqus/Standard, using a coupled thermal-displacement analysis, in stationary state.

The temperature obtained in the thermal model is introduced like a thermal boundary condition in the inner and outer tube wall. There is no heat flux in the inlet and outlet regions of the molten salt, so the temperature of the wall in that part has been assumed equal as the fluid temperature.

Additionally, mechanical boundary conditions are imposed in the model. Receiver tubes are attached to the structure by several clips along their length, preventing them for bending. The distance between clips has been arbitrarily chosen as 2 meter. Also, the upper part of the tube, where the fluid enters, is welded to the structure, so it has been considered encastred. The opposite end of the tube can displace freely. These mechanical boundary conditions are shown in Figure 3.

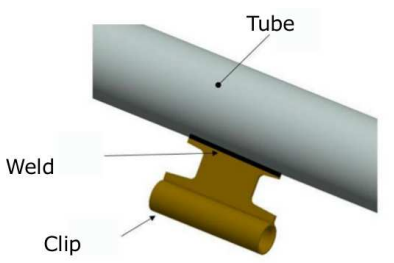

(a)

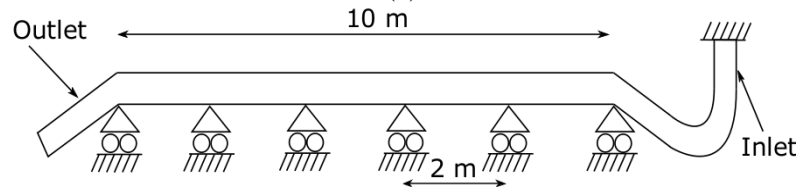

(b)

Fig. 4. (a) Clip detail. (b) Mechanical boundary conditions in thermoelastic model.

The mesh have been generated using shell elements of 2 $\mathrm{mm}$ size. Tube thickness is around one tenth of the diameter, therefore, the tube can be considered as a thin walled cylinder. Although solid elements would be preferable for meshing the model, since we can obtain all the stress components with these elements, computational cost of meshing the whole tube with them is too high, because the tube thickness is extremely small compared with its length and a considerable number of elements would be needed.

\section{Results}

The thermal and mechanical stresses have been obtained for the different boundary conditions explained below.

\section{A. Stress evaluation with different boundary conditions}

In this section the stress in a receiver tube has been characterized for and aiming factor 3 . In this case the mass flow rate of salt is $253.5 \mathrm{~kg} / \mathrm{s}$. To carry out the analysis two different mechanical boundary conditions have been considered.

The first conditions assume that one end of the tube encastred and the other is free (no clips), being the most extended way of calculation in the literature, where stress is only studied in the cross section. In this case, only the thermal stresses are taken into account; being the deformation of the tube equivalent to the one represented in Figure 5.a.

Actually, the tubes are guided by clips to prevent excessive displacements. In this case the tube deformation has been represented in Figure 5.b., with a maximum displacement of $2.64 \mathrm{~mm}$. Mechanical stresses appears due to the tube can't displace freely. The total stress in this case will be the sum of thermal and mechanical stress components. 


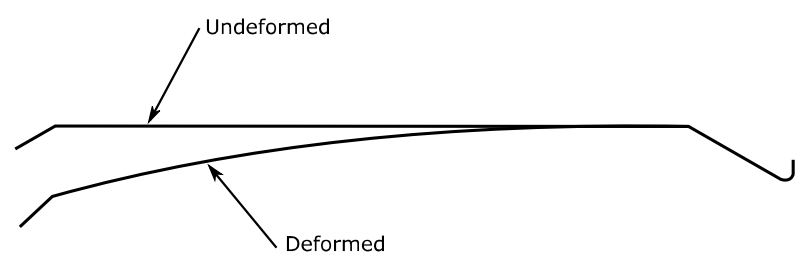

(a)

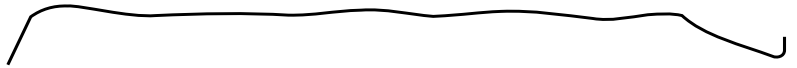

(b)

Fig. 5. Deformation of the tube (a) without clips and scale factor $1 / 6$, (b) with clips and scale factor $250 / 1$.

Figure 6.a shows the Von Mises equivalent stress in the central part of the tube without clips. The maximum stress is found in the central section of the tubes in their face exposed to the heliostat field (upper part in Figure 6), with a value of $186.2 \mathrm{MPa}$. When displacement in the tube is restrained by clips, it cannot bend and the superior part compresses. The equivalent stress now is clearly superior, as Figure 6.b depicts, having a maximum value of 560.7 $\mathrm{MPa}, 3$ times higher than the previous case. Thus, the structural stresses are the double than the thermal stresses and cannot been neglected in solar receivers.

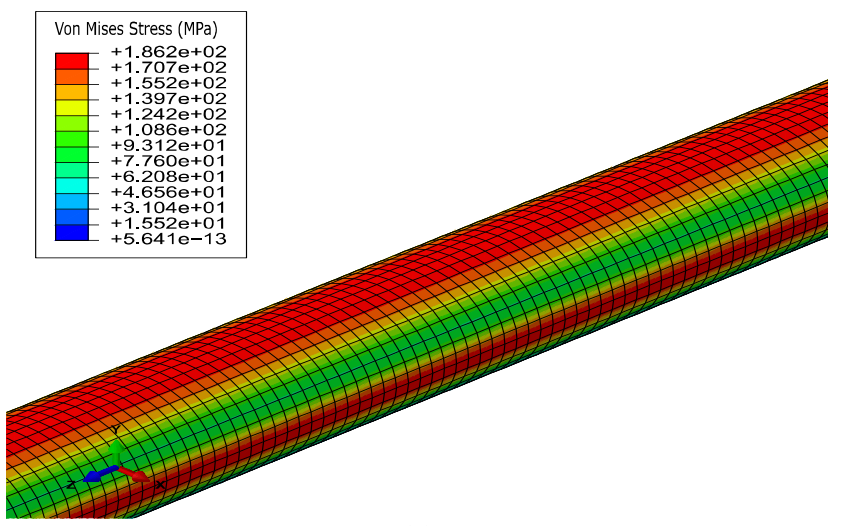

(a)

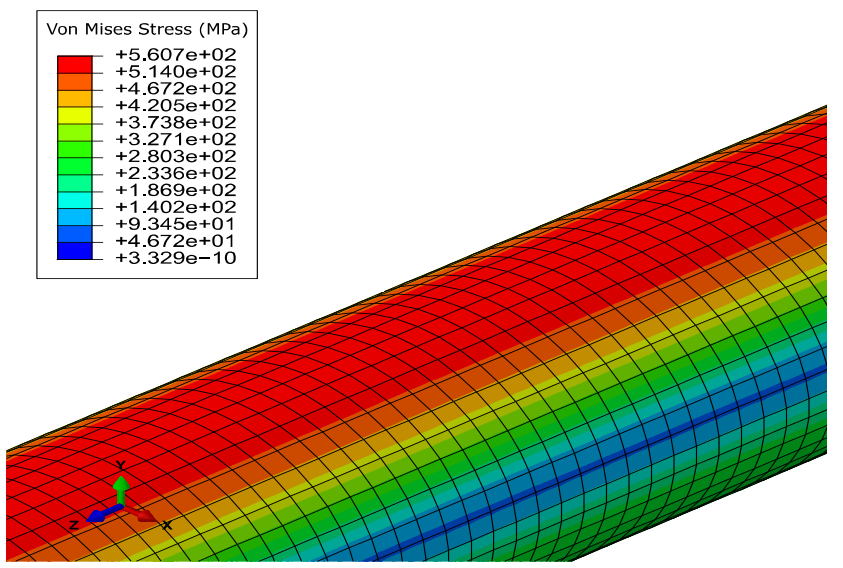

(b)

Fig. 6. Maximum Von Mises stress (a) without clips, (b) with clips.

\section{B. Incident solar flux influence}

Once the importance of considering both types of stresses has been pointed out, the influence of the incident solar flux profile in the total stress has been studied.

Figure 7 depicts the maximum values of incident solar power, the wall temperature and the total stresses along the tube length as a function of the aiming strategy employed in the receiver. This figure corresponds to the most unfavourable panel and circumferential position, which corresponds to the face of the tube faced to the heliostat field in the panel with higher incident power.

In Figure 7 can be seen that the three variables: incident solar flux, wall temperature and Von Misses stress follow a similar pattern; the higher is the peak flux the larger will be the temperature gradient and the total stresses. In Figure 7.c, it can be also noticed that the stress slope changes every 2 meters, coinciding with the clips location.

Thus, when all the heliostats focus to the equator $(\mathrm{k}=3)$ the conditions for the stress are the most adverse. Contrary to the expected the best scenario does not corresponds to the lowest $\mathrm{k}$ factor, where the heat flux is minimum. Although, the global flux is the minimum, the flux distribution is not homogeneous and then there are temperature gradients that generate thermal stresses and tube deformation.

Therefore, to reduce the stresses in the tube receiver the most homogenous incident solar flux $(\mathrm{k}=2)$ is the best option.

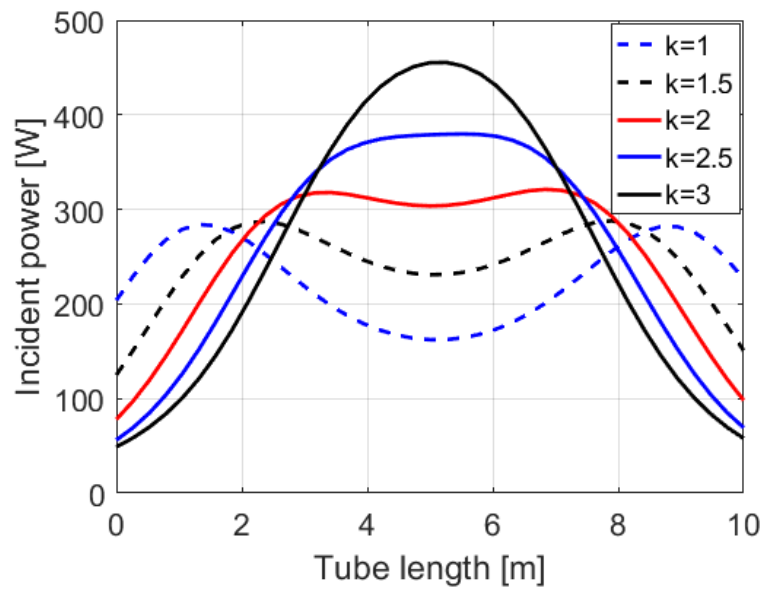

(a) 


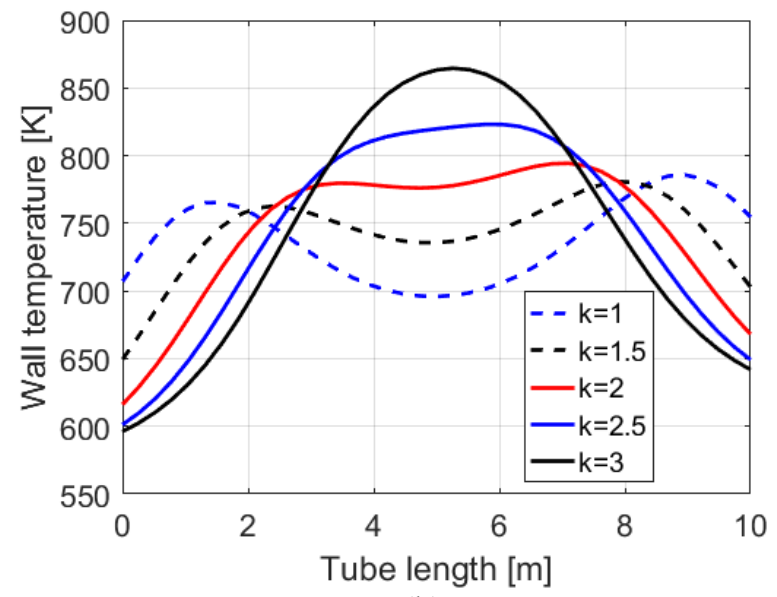

(b)

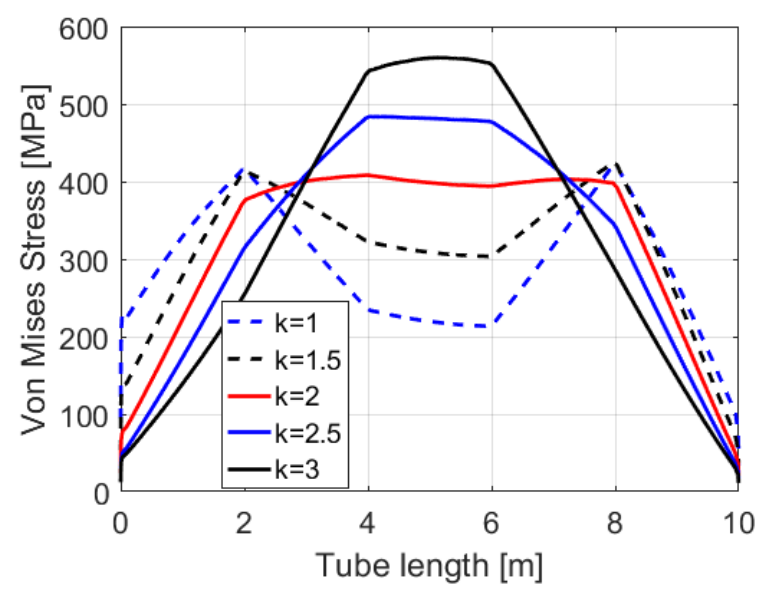

(c)

Fig. 7. (a) Incident power, (b) wall temperature, (c) and Von Misses stresses along the tube length as a function of the aiming strategy employed.

\section{Conclusions}

The study of the stresses in the tubes of the solar receivers are crucial to avoid prompt failure of the receivers. The study of these stresses is complex, because they are caused by circumferential, radial and longitudinal temperature gradient, and also by the mechanical boundary conditions.

In this study the stresses in the receiver tubes have been quantified when no movement restrictions are applied (thermal stresses) and when the mechanical boundary conditions are equivalent to the operational conditions (thermal and mechanical stresses). It has seen that the mechanical stresses are an important component of the total stress, increasing the stress value 2 times with respect to the case with not movement restrictions; so its contribution cannot be neglected.

Finally, the total stresses in the receiver tubes have been quantified for different aiming strategies of the heliostats. It has seen that the reduction of the peak flux is not enough to minimise the total stresses in the tubes. The most effective way to reduce the stresses in the tubes is reducing the temperature gradients and homogenising the incident solar flux, which is reached with aiming factors close to 2 .

\section{Acknowledgement}

This work has been supported by the Iberdrola Fundation Spain under the fellowship "Ayudas a la investigación en energía y medio ambiente".

\section{References}

[1] Gauche, P., Rudman, J., Mabaso, M., Landman, W. A., von Backstrom, T. W., Brent, A. C. System value and progress of CSP. Solar Energy 2017, Vol. 152, pp. 106-139.

[2] Gertig, C., Delgado, A., Hidalgo, C., Ron, R. SoFiA a novel simulation tool for central receiver systems. Energy Procedia 2014, Vol. 49, pp. 1361-1370.

[3] Marugán-Cruz, C., Flores, O., Santana, D., García-Villalba, M. Heat transfer and thermal stresses in a circular tube with a non-uniform heat flux. International Journal of Heat and Mass Transfer 2016, Vol. 96, pp. 256-266.

[4] Du, B.-C., He, Y.-L., Zheng, Z.-J., Cheng, Z.-D. Analysis of thermal stress and fatigue fracture for the solar tower molten salt receiver. Applied Thermal Engineering 2016, Vol. 99, pp. 741-750.

[5] NREL. Concentrating Solar Power Projects, 2017. https://www.nrel.gov/csp/solarpaces/project_detail.cfm/proj ectID $=40$

[6] Special Metals Corporation. Incoloy alloy 800H \& 800HT. SMC-047, 2004

[7] Zavoico, A.B. Solar power tower: Design basis document. Sandia National Laboratories, San Francisco, SAND20012100, pp. 1-148.

[8] Sánchez-González, A., Santana, D. Solar flux distribution on central receivers: a projection method from analytic function. Renewable Energy 2015, Vol. 74, pp. 576-587.

[9] Sánchez-González, A., Rodríguez-Sánchez, M.R., Santana, D. Aiming factor to flatten the flux distribution on cylindrical receivers. Send for publication to Energy, 2018.

[10] Rodríguez-Sánchez, M.R., Soria-Verdugo, A., AlmendrosIbáñez, J. A., Acosta-Iborra, A., Santana, D. Thermal design guidelines of solar power towers. Applied Thermal Engineering 2004, Vol. 63 (1), pp. 428-438. 